Illinois State University

ISU ReD: Research and eData

Theses and Dissertations

$12-7-2018$

\title{
Examining the Learning of Students Participating in an Interactive Simulated Patient Experience
}

Mary Smyers

Illinois State University, marymark1@gmail.com

Follow this and additional works at: https://ir.library.illinoisstate.edu/etd

Part of the Speech and Hearing Science Commons, and the Speech Pathology and Audiology Commons

\section{Recommended Citation}

Smyers, Mary, "Examining the Learning of Students Participating in an Interactive Simulated Patient Experience" (2018). Theses and Dissertations. 1046.

https://ir.library.illinoisstate.edu/etd/1046

This Thesis is brought to you for free and open access by ISU ReD: Research and eData. It has been accepted for inclusion in Theses and Dissertations by an authorized administrator of ISU ReD: Research and eData. For more information, please contact ISUReD@ilstu.edu. 


\section{EXAMINING THE LEARNING OF STUDENTS PARTICIPATING IN AN INTERACTIVE SIMULATED PATIENT EXPERIENCE}

\section{MARY SMYERS}

45 Pages

\section{Abstract}

Simulated patients are becoming increasingly used in the educational program of future speech-language pathologists. The use of standardized patients provides the opportunity to teach students clinical skills in a controlled environment (Bradley, 2006; Zraick, 2012). Simucase, a speech-language pathology software program, allows clinicians to practice their assessment and treatment skills on virtual patients and is a valid method when teaching clinical skills. Thus, this project examined five undergraduate senior clinicians' performance and reflection about the Simucase program and their own clinical knowledge. The undergraduate student clinicians engaged in controlled simulation experiences that shared similar characteristics to their current clients, and then reflected upon their experiences via self-report questionnaires. Students engaged in simulations in two different modes. When working in the learning mode, students were provided with feedback about their clinical decision-making. In the assessment mode, no feedback was provided. Results indicated that students spent significantly more time interacting with simulated cases, as well as significantly increased competency scores when utilizing in the assessment mode. Students' reflections about their experience with Simucase indicated increased confidence in utilizing the program and when providing treatment. However, students' confidence decreased in taking data and making an appropriate clinical decision likely because their experience with Simucase allowed them to reflect on deficits in their knowledge and skills. 
This study demonstrates the need for continued research within communication sciences and disorders fields as to the efficacy of the use of simulated patients with undergraduate students. Additionally, a further study is needed to better understand the strengths and weaknesses of different Simucase modes on student learning.

KEYWORDS: Simucase; simulated patients; learning modes; clinical learning; simulated experience 
EXAMINING THE LEARNING OF STUDENTS PARTICIPATING IN AN INTERACTIVE SIMULATED PATIENT EXPERIENCE

MARY SMYERS

AThesis Submitted in Partial Fulfillment of the Requirements for the Degree of MASTER OF SCIENCE

Department of Communication Sciences and Disorders

ILLINOIS STATE UNIVERSITY 
Copyright 2019 Mary Smyers 
EXAMINING THE LEARNING OF STUDENTS PARTICIPATING IN AN INTERACTIVE SIMULATED PATIENT EXPERIENCE

MARY SMYERS

COMMITTEE MEMBERS:

Jennifer Friberg, Co-Chair

Lisa Vinney, Co-Chair

Tricia Larkin

Julie Schumacher 


\section{ACKNOWLEDGMENTS}

I would like to start off by thanking my parents for the abundance of love and support that you have shown me throughout my life. Thank you for always being my rock and encourager. I am grateful that you always encouraged me to do my best. I am so lucky to be your daughter and thank you for always supporting my dreams. I do not know what I would do without you. Andy, thank you for always supporting me and pushing me to achieve more than I have ever thought was possible. To the Blue Group, thank you for helping me achieve this goal and for continually cheering me on.

To my committee, Mrs. Larkin and Dr. Schumacher, thank you for your support and advice throughout this journey. I have learned so much from you throughout this process, and I appreciate your guidance. To my Co-chairs, Drs. Friberg and Vinney, the words, thank you, will never accurately describe how grateful I am to be able to work with you. I am extremely grateful for your open arms since our first research project together. Thank you for all of your guidance, support, and encouragement throughout this process. Both of you have gone above and beyond to help me throughout this journey, and I cherish the time that we have spent together.

M. S. 


\section{CONTENTS}

ACKNOWLEDGMENTS

Page

ACKNOWLEDGMENTS

CONTENTS

TABLES

ii

TABLES

CHAPTER I: INTRODUCTION

Purpose and Implications of Investigation

Research Questions

CHAPTER II: LITERATURE REVIEW

What are Standardized Patients 5

History and Professional Use of Standardized Patients $\quad 6$

$\begin{array}{ll}\text { Standardized Actors } & 6\end{array}$

$\begin{array}{ll}\text { Use of SPs } & 6\end{array}$

$\begin{array}{ll}\text { Use of SPs in Speech-language Pathology } & 7\end{array}$

$\begin{array}{ll}\text { Simulated Patients } & 8\end{array}$

Simulated Patients Use in the Real World 9

$\begin{array}{ll}\text { Simulated Patients in the Classroom } & 10\end{array}$

$\begin{array}{ll}\text { Simucase Virtual Case Studies } & 11\end{array}$

Simucase Learning in the Classroom 11

$\begin{array}{ll}\text { Types of Simucase SimPs } & 12\end{array}$

$\begin{array}{ll}\text { Simucase Modes } & 12\end{array}$

Lack of Evidence to Support the Use of SimPs 13

$\begin{array}{ll}\text { Summary } & 14\end{array}$

$\begin{array}{ll}\text { CHAPTER III: METHODS } & 15\end{array}$ 
$\begin{array}{ll}\text { Purpose } & 15\end{array}$

$\begin{array}{ll}\text { Participants } & 15\end{array}$

$\begin{array}{ll}\text { Processes and Procedures } & 15\end{array}$

$\begin{array}{ll}\text { Pre-simulation } & 16\end{array}$

Cases Selected for Use in Study 16

$\begin{array}{lr}\text { During Simulation } & 18\end{array}$

$\begin{array}{ll}\text { Post-Simulation } & 18\end{array}$

$\begin{array}{ll}\text { Data Analysis } & 18\end{array}$

Bloom's Taxonomy 19

$\begin{array}{ll}\text { CHAPTER IV: RESULTS } & 20\end{array}$

$\begin{array}{ll}\text { Participants } & 20\end{array}$

$\begin{array}{ll}\text { Research Questions } & 20\end{array}$

$\begin{array}{lr}\text { Students' Confidence } & 22\end{array}$

$\begin{array}{ll}\text { Additional Findings } & 22\end{array}$

CHAPTER V: DISCUSSION 24

$\begin{array}{ll}\text { Summary of Study } & 24\end{array}$

Simucase's Role in Clinical Learning 24

Perceptions of Simucase Modes $\quad 26$

$\begin{array}{ll}\text { Engagement within the Simulated Cases } & 27\end{array}$

$\begin{array}{ll}\text { Confidence in Clinical Skills } & 27\end{array}$

$\begin{array}{ll}\text { Additional Findings } & 28\end{array}$

$\begin{array}{ll}\text { Impressions } & 29\end{array}$

$\begin{array}{ll}\text { Limitations } & 29\end{array}$

Conclusion and Further Research $\quad 31$ 
REFERENCES

APPENDIX A: PRE- AND POST-SIMULATION QUESTIONAIRE

APPENDIX B: PRE-SIMULATION SURVEY

44

APPENDIX C: REFLECTION QUESTIONS

45 


\section{TABLES}

Table Page

1. Pre-simulation Survey: Patient Demographics

2. Pre/Post-simulation Questionnaire Results

3. Bloom's Taxonomy Data 38

4. Competency Scores for Learning vs. Assessment Mode 39

5. Competency Scores and Time Spent on Cases Based on Learning 40 and Assessment Modes

6. Bloom's Taxonomy Statements 


\section{CHAPTER I: INTRODUCTION}

Students develop their professional craft by taking advantage of the opportunities presented to them to learn from their peers, professors, course experiences, and readings. Technology has evolved and provides applications for students to utilize various training programs to practice clinical skills. Opportunities to learn abound in most academic programs, and communication sciences and disorders (CSD) is no exception.

One learning experience that is becoming increasingly common in speech-language pathology (SLP), is the use of standardized patients to teach students clinical skills in a controlled environment. A standardized patient (SP) is a person "trained to portray a patient scenario, or an actual patient using their own history and physical exam findings, for the instruction, assessment, or practice of communication and/or examining skills of a health care provider" (Bradley, 2006, pg. 258). Thus, the SP is an individual that demonstrates a realistic case study by acting out a hypothetical patient's illness and findings. As a part of the SP's portrayal of a patient, students engage in interactive clinical practice with SPs across a variety of disorders and conditions. Zraick (2012) considers SPs to be a vital resource for CSD training as course instructors can provide consistent verbal and behavioral feedback to students in a low-risk environment. One variation of the SP is the simulated patient (SimP) (Beyea and Kobokovich, 2004; Gaba, 2004; Zraick, 2012). Recent technological developments have produced SimP opportunities for clinical training in CSD with software programs such as Simucase (Simucase, 2017).

Evidence exists to support the use of SP in clinical training programs, such as CSD. Specifically, research has found students improve their clinical skills by taking a case history when engaging in interviews with SPs (Zraick, 2003). While most studies have examined 
students' clinical growth in specific aspects of the clinical process, limited research examine students' clinical decision-making from assessment through treatment when working with SP cases . With SimP cases, this becomes easier as students are able to engage in simulated assessment, treatment, and receive competency scores for their clinical decision-making (Simucase, 2017). Thus, SimP provides SLP students with the opportunity to explore their clinical abilities and apply findings to their client's needs.

Opportunities to interact with SimPs with specific communication disorders are available through web-based platforms such as Master Clinician and Simucase (Bradley, 2006). Students are given the opportunity to choose a case from a case study library in a variety of areas. Students have the opportunity to learn while receiving feedback throughout a clinical scenario (learning mode), and without the provision of feedback (assessment mode) (Simucase 2017). While these patients are virtual, students have the opportunity to engage in clinical problemsolving skills related to realistic clinical scenarios, enhance their clinical skills before stepping into the therapy room during graduate coursework, and expand their professional skills for continuing education hours after practicing as an SLP (ASHA, 2009).

\section{Purpose and Implications of Investigation}

Although research has documented positive clinical skill development with the use of SP with CSD students, the effectiveness of SimP has not been explored (Zraick, 2003, 2012). Therefore, the purpose of this study is to fill this knowledge gap by exploring potential transfer of skills learned via Simucase to the therapy room. This study also explores also how learning through Simucase (via learning or assessment modes) is best supported. A better understanding of this relationship will be useful to educators so that they may support the development of clinical skills of students enrolled in SLP training programs. Understanding how Simucase may impact students' professional growth may lead to better clinical service delivery. 


\section{Research Questions}

The following research questions have been established regarding SimP:

1. Do undergraduate CSD student clinicians perceive Simucase as a tool that supports their clinical learning?

a. Rationale: Simucase software allows students the opportunity to practice their clinical skills. Typically, Simucase is implemented in graduate-level classes to introduce students to new assessments or therapy scenarios (Simucase, 2017).

b. Hypothesis: Undergraduate student clinicians will have the opportunity develop clinical skills via Simucase. While Simucase would not have been used until graduate school, undergraduate student clinicians have the opportunity to learn more about various clients and intervention techniques earlier in their studies.

2. Is one Simucase mode (learning or assessment) more effective than the other in supporting clinical learning in undergraduate CSD student clinicians?

a. Rationale: Simucase software allows students to practice using assessment and treatment skills with virtual SimPs by allowing students to manage cases based on their clinical judgment. Simucase records student responses throughout the assessment and treatment scenario and provides an overview of clinical "competency" for each completed case. Student have the opportunity to practice their clinical skills in both the learning and assessment mode during a case study; however, it is unclear which of these modes is most effective in facilitating undergraduate students' clinical learning (Simucase, 2017).

b. Hypothesis: Undergraduate student clinicians have the opportunity to practice their skills on various cases utilizing various options and resources. Students will utilize the learning and assessment zone during this research study. Students will 
benefit most from the learning mode because students have the opportunity the receive feedback, which will correlate with their clinical "competency" and their answer selection.

\section{How does student-learning change based on the amount of times students} engage with a clinical case?

a. Rationale: Simucase provides students the opportunity to practice their cases as many times as they wish, but it is unclear how repeated practice with the same case affects learning.

b. Hypothesis: Students will gain confidence in their clinical judgment and skills the more times that they complete a case. Students will be able utilize the clinical skills that they learn in one case and apply them to another. 


\section{CHAPTER II: LITERATURE REVIEW}

\section{What are Standardized Patients?}

Standardized patients (SPs) have existed for centuries and have been used within medical fields in educational and training settings (Bradley, 2006). The use of SP occurs through the use of various methods, typically as professional actors who portray specific patients in a case study or simulated manikins that are used to provide practice in obtaining subjective patient information that is consistent and reliable (Zraick, 2012). Additionally, course instructors ask patients with diagnosed conditions to take part in carefully designed role-playing scenarios to create SP experiences. SPs have been used in these formats to help ensure experience and solidify knowledge and skills via realistic clinical training scenarios (Rosen et al, 2009). Through the use of SPs, students are able to build upon their previous knowledge and experience by practicing and rehearsing real-life scenarios in a safe, non-judgmental environment. As a result, patient care is optimized when students are working with actual patients (Zraick, 2012). In many cases, SPs allow students to eliminate sources of personal or professional discomfort in their clinical practice and minimize harm that can occur when novice clinicians work with various patients for the first time (Cantrell and Deloney, 2007; Zraick, 2012). Through SP experiences, students can be exposed to various client personality types as well as to sensitive topics that students may encounter in the future (Bearnson and Wiker, 2005; Thacker et al, 2007; Taylor, 2011). Many health facilities and universities are now implementing SPs into their curriculum based on the increased demands from various stakeholders to ensure better clinical outcomes by future clinicians. Integration of SPs helps prepare students for eventual independent work with real patients. Students are tasked with generalizing SP experiences to real life clinical practice where they must be able to handle a variety of situations and patient types (Gaba, 2004). 


\section{History and Professional Use of Standardized Patients}

There have been various types of SP models used in the last three decades. Medical Education Reform began utilizing SPs in the second half the $20^{\text {th }}$ century, which allowed undergraduate and graduate students to apply their clinical knowledge in anatomy (Bradley, 2006). Students were able to apply their clinical skills to written case studies by coming up with assessment and treatment plans; The Resuscitation Movement used manikins, which allowed the course instructor/examiner to simulate real-life beyond just written scenarios. The use of manikins allowed students to practice their communication and clinical skills. The last movement is the Anesthetic Simulator that uses simulation through manikins and models that were used for resuscitation, procedures, and other skills that are common practice in the medical setting (Bradley, 2006).

Standardized Actors. The most common type of SP uses simulated actors to demonstrate specific clinical features. Each SP requires an average of four hours of training to properly and accurately portray an individual with a particular condition consistently (Zraick, 2012). The stimulated actor must understand the physical characteristics, emotional impact, secondary characteristics, and behaviors of their condition (Zraick, 2012). These behaviors are typically listed on a checklist to ensure realistic and accurate portrayal of patients in the real world. The simulated actor then 'performs' a practice run with the case administrator to ensure a proper portrayal. The SP then performs their case in front of student clinicians. Simulated actors can be trained to undertake a variety of roles in an SP scenario (e.g., the interview portion of the case history). Thus, student clinicians are able to gain competency in different aspects of assessment and treatment.

Use of SPs. While SPs have been widely used in the last three decades, they are being increasingly utilized in many health-care professions as a part of pre-professional preparation for 
doctors, nurses, and speech-language pathologists. For instance, medical students are using SPs to prepare for Objective Structured Clinical Exams (OSCEs). SPs allow these students to practice and implement various clinical skills to ensure that doctors are prepared to work with patients in the future (Mookherjee, Chang, Boscardin, \& Hauer, 2013). In the field of nursing, SPs are used to expand clinical practice and increase accountability by allowing students to practice their bedside manner and their clinical skills, and essential professional skills in their discipline. Particularly in these professions, SPs allow clinical training programs to manage costs as health care institutions downsize due to community-based patient care (McWilliam and Botwinski, 2010).

Use of SPs in Speech-language Pathology. While there has been limited research on the use of SP in speech-language pathology (SLP), Edwards and colleagues (1995) reported on the use of an SP to portray a 36-year old stroke patient with communication difficulties. As a result of interacting with this SP, students were able to critique their own learning and gain clinical skills (Edwards et al, 2000).

More recently, Zraick and colleagues trained SPs to portray an individual with aphasia to eighteen first-year graduate SLP students completing a neurogenic language disorders class (Zraick et al, 2003). During the study, half the students participated in a practice session with SPs with two additional lectures. The other half of the students did not have the opportunity to participate in a practice session with SPs and only listened to one lecture. The researchers examined how students' interpersonal and communication skills changed as a result of interacting of either condition via two OSCEs. There were no significant differences between the two groups' communication and interpersonal skills, indicating that, in this case, the use of SPs did not result in significant increase in students' clinical learning relative to students who 
received information via a lecture only (Zraick et al, 2003).

In another recent study, SLP students were given the opportunity to practice their interviewing skills on SPs (Lysaght and Hill, 2010). The simulated actors were provided with case histories as well as signs and symptoms of specific communication and speech deficits to exhibit. From there, SLP students conducted a case history interview for the purpose of differentially diagnosing and obtaining additional information. The results of this study indicated that SPs demonstrate a very practical replication of the interview process clinicians typically experience with an actual patient.

\section{Simulated Patients}

Computer-based SimP provides students the opportunity to practice clinical skills from anywhere, as an "in person" standardized actor is not needed for interaction with students. Rather, asynchronous methods are used to achieve the same type of learning. There are several types of computer-based SimP that have been used, including multimedia programs, interactive systems, virtual reality and haptic systems, and integrated simulation. Specifically, multimedia programs have been used in medical settings to teach students aspects of the cardiovascular curriculum through the use of audio and video. (Bradley, 2006). Similarly, interactive systems have been used to demonstrate physiological or pharmacological symptoms, which can be manipulated by the examiner. The instructor will provide feedback based on the decisions and actions that the student selects (Bradley, 2006). For example, students enter virtual reality environment that recreates a typical case that may be seen in a professional setting (Bradley, 2006). The delivery of an interactive system may occur via a gaming-type environment. Virtual reality can also be combined with a part-task trainer. A part-task trainer is an aid that allows students to practice specific professional skills such as ophthalmoscopy. Students can utilize their previously learned skills (via non-SimP experiences such as video gaming) to practice their 
professional training skills during various procedures, such as endoscopy and laparoscopic medical procedures. Finally, virtual reality and haptic systems allow students to practice physical medical procedures to support their learning prior to performing such procedures on real patients (Bradley, 2006). Many medical settings also use integrated simulation, which involves a computer-based manikin acting as the SP (Zraick, 2012). The course instructor manipulates the SP's behaviors and communication via the software to facilitate a particular clinical scenario (Bradley, 2006).

The use of these types of computer-based SPs is sometimes referred to as SimP; as the cases depicted via these methods represent simulations of realistic cases or clinical scenarios.

\section{Simulated Patients' Use in the Real World}

SimPs allow for the development of real-world clinical application skills despite students practicing these skills outside the physical environment of the traditional classroom or clinic. In

particular, SimPs allow students to demonstrate their knowledge and practice their clinical skills without direct patient contact (Zraick, 2012). By continuing to practice routine training with SimP, professionals can grow their clinical skills and ensure that they are providing adequate and appropriate treatment for all patients based on their professional code of ethics

While it is important to practice clinical routines, it is also vital to practice complex clinical cases, such as collecting a case history or providing assessments. In doing so, professionals train their minds to react to a patient's needs and maintain patient safety. Professionals continue to train and practice complex scenarios to ensure the proper outcomes. SimP practice reduces risks to actual patients because it allows the learner to avoid mistakes in the future. SimP can act as an intervention bridge, allowing examiners to train and retain 
information for future real-world use. The SimP will ensure that standards are met based on the student's overall performance (Bradley, 2006).

\section{Simulated Patients in the Classroom}

The use of SimP as part of a university training program for health care providers allows students to learn and rehearse their clinical knowledge and communication skills at various

levels. Students use routine procedures when interacting with SimPs, which allows them to rotate or switch between basic to advanced skills and simple to complex situations (Gaba, 2004). The students have the opportunity to select cases based on their interest, experience, and educational level. SimPs can also be used to teach students' skills needed for crisis resource management in simple and complex cases. Students can use SimPs to rehearse, plan, and schedule various intervention tasks from the information that was previously collected in a case history interview and results from assessments. Further, students can be assessed with SimPs at various levels within their educational sequence (Harder, 2010). Normally, SimPs are used in introductory courses to teach and maintain early stage clinical skills. Students can then become more experienced over time through work with both simulated and real patients (Hill et al, 2010). Students are able to use the knowledge from simulated cases and apply it to future professional situations (Zraick, 2012).

Similar to the use of SPs, the use of SimPs in SLP curriculum allows students to learn and assess, which allows educators to evaluate how their curriculum is likely to transfer to clinical practice. This curricular tool allows students to learn in a safe and supportive educational environment because students are aware that they can learn freely without the fear of making a mistake (Bradley, 2006). The students are gaining clinical experience, which they will be able to reflect upon and utilize in the field. Students are also given the opportunity to advance throughout various sections at their convenience, and their clinical skill growth can be 
continuously assessed. SimP benefits students with opportunities to practice clinical skills, use professional language, and gain knowledge for interprofessional practices. Typically, SimP is a positive addition to any program because students can gain valuable clinical skills and learn from their mistakes, rather than fear how they might affect real patients (Zraick, 2012). For example, Rose, Copley and Scarinci (2017) found increases in undergraduate SLP students' professional knowledge and confidence after they completed a workshop focused on simulating an acute care hospital setting. Likewise, Banski et.al (2018) found that students developed interpersonal and professional skills after a 15-minute session interacting with a SimP with mild dementia.

\section{Simucase Virtual Case Studies}

Simucase is an interactive, internet-based software program designed for SLP students to practice the assessment and intervention process with SimPs. Creators of the Simucase program claim their software supports critical learning via simulated, risk-free practice, and learnercentered experience through repeated practice (Simucase, 2017; Jansen, Johnson, Williams, Pantalone \& Ondo, 2014b; Jansen, Johnson, Williams, Pantalone \& Ondo, 2014a).

Simucase Learning in the Classroom. Students using Simucase are able to work in collaborative groups or individually based on instructor preference and student learning needs. Groups can be utilized to motivate students to compete for the highest score or to share their experiences while completing the case. Scores are based on overall competency results, which are calculated based upon the questions selected within the case studies. Individually, students are able to practice new skills. Simucase also encourages students to keep a reflective journal (Simucase, 2017 Jansen, Johnson, Williams, Pantalone \& Ondo, 2014b; Clark, Yates Early, \& Moulton, 2010). Instructors are advised to hold a debriefing session after completing a Simucase 
to allow students the opportunity to ask questions, discuss areas of strengths and weakness, indicate any difficulties, and gain a broader understanding of the patient at hand (Cantrell, 2008; Jansen, Johnson, Williams, Pantalone \& Ondo, 2014a).

Types of Simucase SimPs. Simulated cases were developed by expert practitioners to reflect typical clinical practice patterns across a variety of setting in the United States. Each Simucase's SimP has been evaluated to insure evidence-based practice implementation and consistency in scoring procedures. All simulated cases are categorized as screenings, assessments, or intervention.

- Screening cases allows student to practice providing a comprehensive screening protocol to a SimP.

- Assessment cases elicit diagnostic skills for patients with potential communication and/or swallow disorders. In the assessment-focused cases, students gain experience in all areas of a comprehensive assessment including: case history review, interview, interprofessional communication, assessment administration, and recommendations. After completing each assessment case, students may be tasked with creating a comprehensive diagnostic report, individualized education plan, evaluation team report, lesson plan, or intervention plan (Simucase, 2017).

- Intervention cases allow students to implement treatment practice associated with goals and objectives that align to the profile of and diagnostic findings for a SimP (Simucase, 2017).

Simucase Modes. There are two modes in the Simucase program, the learning mode and the assessment mode. The learning mode allows students to receive feedback regarding their 
performance throughout the case to assist in learning, such as "Your good listening skills are paying off. Keep up the good work!" and "Reflect upon your selection and listen carefully to the information provided" (Simucase, 2017; Jansen, Johnson, Williams, Pantalone \& Ondo, 2014a).

On the other hand, the assessment mode evaluates the student's overall performance without any specific feedback regarding users' clinical decisions as they move through the case. At the end of each SimP case in either mode, students receive a score and a competency rating. A score of 90 percent and higher correlates to an advanced mastery level, with 70 to 89 percent correlating to developing mastery, and a score of less than 70 percent overall indicating a students' emerging clinical mastery (Simucase, 2017). Students may complete a case multiple times. Thus, it is likely that the more times they complete the same case, the more likely they are to see their problem solving and clinical skills improve. Competency scores are based on the American Speech-Language-Hearing Association's Knowledge and Skills Acquisition (KASA) standards (ASHA, 2009). Each case study aligns with specific KASA standards, which serve to track student performance. Based on these learning opportunities, Simucase has transformed the SimP process by creating a standardized program that enhances clinical skills and judgment.

\section{Lack of Evidence to Support the Use of SimPs}

While SimP is used in teaching environments, there is a lack of research to understand how students are benefiting from SimP. Typically, professionals are creating their own measurement scales based on the SP case, which leads to lack of evidence-based practice. It is beneficial for professionals to examine various learning theories, such as behaviorism, social constructive, reflective learning, and simulated learning to create various measurement scales for SPs and SimPs (Bradley, 2006). These theories are beneficial for understanding the components that SP has on students' overall learning in specific areas (Harder, 2010). This research study 
will use reflective and simulated learning to examine how students learn, connect, and apply knowledge to future patients.

In addition, there has only been a handful of published research for SP in SLP. Edwards et al. (1995) focused on the use of SP who was a 36-year old woman who had a stroke. The students used her as a SP to practice assessing a patient with a neurogenic language disorder (Zraick, 2012). In addition, Zraick et al (2003) used a SP that had aphasia for a neurogenic language disorders class. Students were tasked with working on their communication and interpersonal skills and rated on their performance. These research studies show that students use SP to teach additional communication skills; however, these studies did not focus entirely on clinically-based knowledge, such as differential diagnosis and intervention design.

\section{Summary}

$\mathrm{SP}$ is used throughout healthcare provider training programs. There are various forms of SP; however, the most commonly used are virtual SPs, known as SimP. Simucase is a computer program with a variety of SimPs for student clinicians at the undergraduate and graduate levels. Simucase provides students with the opportunity to practice their assessment, intervention, and screening skills, to support future or current evidence-based SLP practice. 


\section{CHAPTER III: METHODS}

\section{Purpose}

The purpose of this research was to investigate whether Simucase is a valid method to use when teaching clinical skills by examining how students clinical learning was shaped by its use. Additionally, this project explored the impact of student learning in various modes of Simucase and investigated undergraduate senior clinicians' performance and reflection about the Simucase program and their own clinical knowledge and skills.

\section{Participants}

Seventeen undergraduate students were recruited from CSD 308: Undergraduate Clinical Experiences, a course which allows undergraduate seniors to provide speech therapy in a mentored and supervised clinical setting. These students were recommended for CSD 308 by their prior course instructors based on their demonstrated academic and clinical abilities. Of the 17 students recruited for this study, five agreed to participate. Each of these individuals were women between the ages of 20 and 22. Illinois State University's Institutional Review Board approved this project.

\section{Processes and Procedures}

All data were collected using a Google poll which allowed for asynchronous collection of information from all participants. Participants were randomly assigned into one of two groups (Groups A and B) based on the order the undergraduate student clinicians submitted their consent form to the researcher. Each participant was assigned two simulated patient cases (Anna and Alex) to complete using Simucase software. In order to reduce bias, each participant completed these cases in a different order. Group A (i.e. participants one, three, and five) completed Anna's case in the learning mode and then completed Alex's case in the assessment mode. Group B (i.e., participants two and four) completed Anna's case in the assessment mode 
and Alex's case in the learning mode. From there, the researcher randomized the order that each case was completed across participants in each group. Thus, some Group A members may have completed Alex's case first, while others completed Anna's case first.

Pre-simulation. Participants completed a pre-simulation questionnaire and a presimulation survey online prior to all scheduled simulation activities. The pre-simulation survey consisted of seven multiple choice questions that focused on each participant's patient demographics and the clinician's coursework in regard to its alignment with the assigned Simucase experiences. See Appendix A for a copy of the pre-simulation survey. The presimulation questionnaire contained twelve questions and asked participants to rate their confidence on a Likert-type scale in order to understand each participant's confidence with regard to various clinical skills. The questionnaire was adapted from prior questionnaires focused on clinician confidence in efficiently and skillfully taking a case history of an SP (McWilliam \& Botwinski, 2010); and Zraick et al., 2003)). See Appendix B for a copy of the pre-simulation questionnaire.

The questionnaire and survey were sent in advance to participants via a link through their university email. The email stated that the participants were to complete the pre-simulation questionnaire and survey prior to their scheduled simulation time. Following completion of these tasks, participants were scheduled to complete their assigned simulation activities. Each simulation activity lasted for approximately two-hours.

Cases Selected for Use in Study. In order to practice as a speech-language pathologist, students acquire theoretical knowledge and clinical experiences for professional practice by completing a required master's degree program. Undergraduate student clinicians typically have foundational knowledge from their early coursework in speech sound disorders and child language disorders that informs clinical practice. Based on early exposure to these topics, 
undergraduate student clinicians in CSD 308 primarily work with articulation and language clients as part of their undergraduate clinical practice. Thus, the simulated intervention cases selected for use in this study were focused on articulation clients because recruited participants had the proper foundational knowledge to complete them with some level of competency.

Depending on which group they were assigned to, participants completed each of the following Simucase cases in either learning or assessment modes:

- Anna's intervention case focused on a four-year-old girl with an articulation error. An articulation error is when an individual struggles to produce a specific sound correctly and clearly, which can affect the child's intelligibility (ASHA, 2018). Anna struggled to produce the $/ \mathrm{k} /$ sound.

- Alex's intervention case is focused on an eight-year-old boy with a speech sound disorder with a singular speech error. A speech sound disorder is when an individual struggles to produce some sounds correctly because the individual takes longer to learn how to produce classes of sounds (ASHA, 2018). A speech sound disorder can be classified as an articulation error. Alex struggled to produce the $/ \mathrm{r} /$ sound.

As indicated previously, Group A completed Anna's case in the learning mode, and Alex's case in the assessment mode. Group B completed the same two intervention cases but completed Anna's case in assessment mode and Alex's case in learning mode. The students received an overall score out of a hundred percent for the intervention case, which correlated with a competency rating for each case. Competency percentage scores were used for subsequent quantitative analysis.

During Simulation. Participants were instructed to bring their laptops to Fairchild Hall on the Illinois State University campus to complete their SimP case. The examiner provided 
information relative to the case they completed, including each simulated patient's name, whether the case should be completed in assessment or learning mode, and login information. The investigator, who instructed research participants on how to utilize the Simucase software was present as participants completed their cases in order to address any procedural questions raised. The investigator did not answer any content-related questions asked by the participants.

Post-simulation. After the completion of each intervention case, participants answered ten short answer, post-simulation reflection questions to describe their experiences with each simulation activity and the potential applications of any learning. A list of these reflection questions can be found within Appendix C. Once all simulations and reflections were completed, participants also completed a post-simulation questionnaire. The post-simulation questionnaire contained the same questions from the pre-questionnaire and sought to ascertain participants' perceptions related to their clinical confidence after the SimP experiences. Pre and post questionnaire data were compared to measure changes in confidence (see Appendix A).

\section{Data Analysis}

This research study used both qualitative and quantitative measures of data analysis. Quantitative analysis was used to calculate measures of central tendency (i.e., mean, median, mode, and standard deviation) for the data collected via the pre-simulation survey, and presimulation and post-simulation questionnaires. Due to the small sample size, a Wilcoxon signedrank test was used to determine whether significant differences were found between students' competency scores and time spent on cases in the Assessment versus Learning modes. Alpha level was set at .05 .

All post-simulation reflection questions were analyzed using qualitative methods. Specifically, data were analyzed through categorical analysis, wherein the researcher arranged data from reflections into common themes. Contents within each theme were then analyzed using 
Bloom's Taxonomy to understand the complexity of the learning that occurred across simulation experiences. All analyses were conducted by the primary researchers. Inter-rater reliability was measured at over $90 \%$.

Bloom's Taxonomy. Bloom's taxonomy provides a specific way to differentiate higher levels of cognitive processing from lower levels (Bloom, Englehart, Furst, Hill, \& Krathwohl, 1956). Specifically, when students answer reflection questions, their responses reflect one of Bloom's taxonomy levels. Thus, in this study, statements made in response to reflection questions were coded based on which level of Bloom's taxonomy they fit under (knowledge, comprehension, application, analysis, synthesis and evaluation, and analysis) (Vinney, Friberg, \& Smyers, in press). Below is an example of the cognitive skills used at each level during the simulated case with an example of the evolving cognitive skills utilized:

- Knowledge (labeling different components of a clinical case)

- Understanding (matching relevant information to a treatment plan)

- Application (predicting resulting data from assessment information)

- Analysis (interpreting case information to determine potential concerns based on various professionals and case history patterns)

- Synthesis (identifying tasks that may determine the integrity of these assumptions)

- Evaluation (providing a rationale for or against the tasks noted above under Synthesis.)

The number of statements that fell under each code were tallied. Examples of the criteria used to code each reflection statement into a cognitive skill level are provided in Table 6. 


\section{CHAPTER IV: RESULTS}

Data were analyzed from all pre- and post-simulation questionnaires, the pre-simulation survey, and post-simulation reflections returned by participants.

\section{Participants}

Demographic data is provided in Table 1 . The average age of the five participants was 21 years old, with a minimum age of 20 and a maximum age of 22. All five participants completed the pre- and post-stimulation survey and questionnaire, as well as post-simulation reflection questions. Four out of the five participants completed a class in clinical methods prior to their undergraduate clinical experience in CSD 308. Students enrolled in CSD 308 were treating clients with articulation/phonology, fluency, and/or language disorders. Each of the five participants worked with one client each during the semester this research project was completed. Four of these five clients were children.

\section{Research Questions}

This study addressed three research questions regarding Simucase as a clinical teaching tool. Data addressing each question will be provided in a reference table, which is correlated to each question below:

1. Do undergraduate CSD student clinicians perceive Simucase as a tool that supports their clinical learning?

Undergraduate student clinicians' responses to reflection questions (see Appendix C) indicated that they perceived Simucase to be supportive of their learning. Based on the results, most reflection statements were coded under comprehension or analysis. This indicates that students' Simucase experience may have facilitated students to engage in thinking and learning that required both low- and high-level cognitive processes (see Table 6). Students tended to 
focus on fact-based clinical information that was provided throughout the Simucase experience. In addition, students often broke down clinical case information into smaller parts to make sense of an entire case.

2. Is one Simucase mode (learning or assessment) more effective than the other in supporting clinical learning in undergraduate CSD student clinicians?

Each participant completed their assigned cases. Based on competency scores across all participants for these cases, students in both Groups A and B obtained greater than average clinical mastery, as scored by Simucase, in the assessment mode (48\%) as opposed to the learning mode (30\%). These percentages were averaged based upon each participant's competency scores. Results indicate that participants demonstrated better simulated clinical performance when utilizing the assessment mode regardless of the intervention case completed and the order of completion. For example, participant one completed the learning mode first (36\%) and assessment mode second (75\%). While participant three completed the assessment mode case first (61\%) and the learning mode case second (60\%); however, both participants performed better on the assessment mode ( $75 \%$ and $61 \%)$ compared to the learning mode (36\% and $60 \%$ ). For additional information, please reference Table 5 for each competency score by participant and Table 6 for the average competency scores for learning and assessment modes. A Wilcoxon signed-rank test confirmed trends in the raw data and revealed that there were significantly greater competency scores in the assessment $(\mathrm{mdn}=36)$ versus learning modes $(\mathrm{mdn}=23 \mathrm{z}=-2.03, \mathrm{p}=.042)$. 


\section{How does student-learning change based on the amount of time students engage}

with a clinical case?

Further, the Wilcoxon signed-rank test revealed that participants spent significantly greater amounts of time on cases in the assessment $(\mathrm{mdn}=44)$ versus learning mode $(\mathrm{mdn}=40 \mathrm{z}=-$ 2.02, $\mathrm{p}=.04$; See Table 5).

\section{Students' Confidence}

Each participant completed a pre and post simulation questionnaire. After review of the mean average rating of the pre and post questionnaire, students' confidence in the process of utilizing the Simucase software program and providing treatment increased. However, confidence decreased in taking data and making appropriate clinical decisions from pre to post use of Simucase. For additional information, please reference Table 2.

\section{Additional Findings}

Based on open-ended responses to the reflection questions, participants utilized metacognitive skills to recognize areas where additional clinical growth is required. Students indicated additional clinical experience was necessary in regard to collaboration, taking data, adapting therapy activities, and applying prior knowledge from previous coursework. The participants indicated that they had limited knowledge in regard to these areas and describe specific ways that they would be able to gain experience, such as through additional clinical experience and learning from professionals working in the field. In addition, the students indicated growth in utilizing the program as well as providing treatment. Students were able to reflect upon their own learning and previous clinical knowledge to indicate transferable skills and experiences.

Participants indicated that, through the completion of both simulated cases, they were able to improve their clinical skills. Specifically, one participant noted that Simucase facilitated, 
“foundational skills, which will benefit providing therapy in the future." In addition, students indicated that Simucase provided a clinical framework for thinking about treatment. Likewise, participants indicated that this experience allowed them to evaluate their current caseload by collecting a case history, communicating with collaborators, completing assessments, and creating recommendations. From this framework, students were able to look at various components and facts that impacted their current client's growth and determine which of their clinical skills needed additional growth. 


\section{CHAPTER V: DISCUSSION}

\section{Summary of Study}

The purpose of the current study was to explore students' learning while interacting with simulated patients through Simucase. This study also sought to determine if Simucase is a supportive tool in clinical learning, as well as if one simulated mode was more effective than another.

\section{Simucase Role in Clinical Learning}

Clinical learning was indicated through reflective statements after the completion of each Simucase case. Students' reflective statements regarding their experience with Simucase were primarily "comprehension" and "analysis" statements when analyzed through the lens of Bloom's taxonomy. This indicates that students were engaging in both high and low levels of cognitive processing throughout their Simucase case studies. The uses of comprehension statements demonstrate that students were able to focus and understand each individual component as a whole, before manipulating the information. Students tended to want to understand case facts before completing any assessment and intervention activities. In addition, students provided many analysis statements that were indicative of their efforts at clinical decision-making during intervention activities, assessment measures, and recommendations for each client.

The students were able to choose from a field of options in each section, such as collaboration, assessment, intervention activities and recommendations. Students' choices were classified by Simucase as reflective answers (i.e. answers that are appropriate and result in a point), acceptable (i.e. answers that are appropriate but not always necessary in each area, which results in no points), or rejected options (i.e. answers that are inappropriate which will result in a deduction of a point) (Simucase, 2017). This point system correlates to an overall competency 
score which allows students to reflect upon their learning in each clinical skill area. Students tended to complete the task quickly without choosing to repeat the case study or review the case study transcript to understand their errors. By doing so, students did not utilize the opportunity to review their clinical answers on their transcript to understand where clinical skill breakdowns were occurring. Based on the reflection statements, students indicated specific areas where they struggled; however, they did not take the time to understand the results transcript as a whole. It should be noted that one participant asked the researcher after the completion of the second case study how to interpret the assessment results. Thus, it is possible that participants were unclear on how to use the transcript provided to evaluate their clinical skills.

For future research studies, the researchers should take the time to explain how to read the assessment results transcript to understand the purpose of Simucase, as well as each component. From there, the students will be able to learn from their mistakes and have the opportunity to improve overall clinical growth when they complete the same case study again. After the student is aware of their clinical errors, as indicated by the assessment results transcript, the students should be provided with the option to complete the Simucase case study again, so that they might learn from prior mistakes to improve their clinical skills and decisionmaking.

In addition, all participants indicated that it would have been helpful to have the examiner walk them through the simulation structure more intensely. For example, students indicated, "I had a hard time understanding how to use the clipboard and think I could have used it to my advantage" and "very confusing to use for someone who was not instructed." Students indicated that they appreciated how the program was a simulated computer experience, like a video-game; however, when the students were required to utilize and locate clinical information, they had difficulty due to no previous exposure to the software. This may have affected their overall 
clinical competency scores and the number of coded reflective statements that fell under each level of Bloom's Taxonomy.

\section{Perceptions of Simucase Modes}

Students demonstrated higher scores when they completed a simulated case in the assessment mode as opposed to the learning mode. The students also spent significantly more time working on cases that were completed in the assessment mode. In assessment mode, students were tasked with completing the intervention case without any additional feedback, while in learning mode, students were able to utilize feedback from the Simucase program. Students indicated "I found that I was better able to provide therapy based off of the feedback this program provided me." On the other hand, the assessment mode allows students to assess their own learning because there is no additional support for the student or automatic feedback. While automatic feedback is beneficial to ensure students are on the right track, students tend to click answers until they select the right one without always thinking about their selection.

Thus, it is hypothesized that students tended to demonstrate more growth in competency scores and utilized additional time in the assessment mode by applying executive function skills (i.e. working memory, planning, organizing, self-monitoring and cognitive flexibility). Students were able to utilize problem solving skills to select appropriate assessment measures and determine the best course of treatment. For example, one student stated, "I asked many questions to the child to gather a language sample and asked the parent multiple questions to understand the nature of the problem." In addition, the clinician is able to be more efficient and organized within their selection because they are utilizing the process of elimination to select the most appropriate action. Despite the mode of completion, both modes provided students the opportunity to gain clinical skills that they were not exposed to before. Students were able to comprehend and analyze these skills. 


\section{Engagement within the Simulated Cases}

After the submission of each simulated case, the students demonstrated that more time was spent engaging within the assessment mode across all participants. It can be assumed that the students tended to spend more time in the assessment mode because they had no additional feedback and were required to utilize executive function skills to complete the intervention case. This is positively corelated with competency scores in the assessment mode because students were required to problem-solve throughout the duration of the case.

It should be noted that two participants recognized verbally that they were able to stop and restart the intervention case at any time; however, they wished not to because of additional educational tasks. In addition, one participant asked if it was possible to complete the case again; however, they chose not to. Based on these verbal observations, it can be assumed that most participants were not aware that they could repeat a case and that participants' other competing demands also affected the time and effort they put into completing each case.

\section{Confidence in Clinical Skills}

After the completion of this research study, participants indicated greater confidence in understanding how to utilize the Simucase program and in their ability to provide treatment. Participants did have some experience in picking out intervention activities for their current "real" client which was likely reinforced by their Simucase experience. In addition, students tend to pick up Simucase quickly because of its similar format across intervention cases.

Students demonstrated some decreased confidence in their data collection and clinical decision-making skills following their Simucase experience. These students were currently working with their first client in a clinical setting; therefore, students were learning the basic processes for collecting data and making clinical decisions. Thus, declines in confidence may be attributed to a lack of clinical experience and exposure within the therapy room and the gaps in 
clinical knowledge and skills revealed by their interaction with Simucase. While students indicated that they still have a lot to learn, they also stated, "I still feel confident and capable when I am administering therapy".

Based on data reported via the pre- and post-simulation questionnaire, students were able to utilize metacognitive skills to realistically assess their current knowledge and skills based on exposure to new and different skills required by their simulated experience. For example, one participant stated, "I am sure I still made mistakes in the answers I chose, but I was definitely more confident in my choices." Further research is required to examine the future impact that Simucase has on students' learning across time.

\section{Additional Findings}

All participants indicated that they were able to engage and apply their clinical skills to real-life patients after their experience with Simucase. The students indicated that Simucase provided them with the opportunity to enhance their own hands-on skills compared to the skills they learned in the classroom. While each client is different, all undergraduate students felt that they had the opportunity to grow within various clinical areas. The clinical skills that the clinician obtained and utilized from the Simucase program, allowed the clinician to reflect upon the clinician's future treatment of their "real-life" and future clients. Based on reflective learning through simulated reflection questions, students were able to indicate the impact of various treatment methods, which in turn provides them with the opportunity to apply additional skills to their clinical cases.

\section{Impressions}

The results from the sample indicated that, on average, students demonstrated higher competency scores in assessment as opposed to learning mode. Further, results appear to indicate that the more time that an undergraduate student clinician spends engaging with a SimP case, the 
more likely the student is able to understand their strengths and weaknesses as a clinician (Simucase, 2017). Students were able to demonstrate metacognitive skills during the completion of the pre and post confidence questionnaire, as well as in their reflective statements. Based on the answers, students applied their clinical skills from simulated patient to their real-life patients. In addition, students were able to indicate areas where additional growth (i.e. taking data and clinical decision making) and improvement (i.e. utilizing Simucase and providing treatment) were needed. These findings were based on a small number of participants. Thus, further research is necessary to substantiate and build upon the trends discussed. study.

\section{Limitations}

A limitation of this research was a small sample size composed of undergraduate seniors with foundational knowledge across topics in communication sciences and disorders at a university. These results should be interpreted as pilot data, with generalizability not assumed to other contexts or populations without further study. Thus, continued research is needed within to examine efficacy of the use of simulated patients with undergraduate CSD students.

Additionally, further study is needed to better understand the strengths and weaknesses of different Simucase modes in student learning. Students indicated that Simucase provided various clinical experiences; however, at the completion of the case study they wished they had feedback on their clinical choices in each mode.

Students noted the visual aspects of the experience in their reflection. For example, "It was beneficial to watch the circle move and receive feedback" in the learning mode, "while no feedback was provided" in the assessment mode. While students were able to pick up on the visual feedback aspects, students still struggled with understanding other strengths and weaknesses from other Simucase cases. Further, education is required at the beginning of the research experience to ensure that students are aware of the Simucase functions, as well as the 
purpose of each mode. In addition, more instruction is required for participants who are unfamiliar with the Simucase and its clinical tools (i.e. clipboard, assessment documents and descriptions of assessments/interventions, restarting the case). It might be beneficial for the researcher to explain how to utilize the feedback (i.e. green feedback is positive feedback where the clinician is making appropriate clinical decisions, while red feedback is a warning that the clinician is not making correct clinical decisions) in the future. By allowing additional instructional time, the students will be able to gain additional clinical skills, which will enhance their clinical learning.

It should be noted that students willingly participated in this research opportunity without any compensation for their time. Therefore, students tended to focus on completing the case by quickly getting the desired feedback in the learning mode. By rushing through the task, the students were not taking time to reflect upon the feedback Simucase provided or practice aspects of the case multiple times. Another consideration for participants' motivation is a lack of interest in the assigned cases. This sentiment was reflected in some student reflections. Other students indicated lack of motivation to complete the case because the SimP was not engaged in therapy. It is impossible to know the extent of motivation and interest in the case because the undergraduate senior clinicians were volunteering to complete Simucases for their personal clinical experiences.

\section{Conclusion and Further Research}

The research study sought to explore the impact of Simucase as a method to teach clinical skills by using SimP. Due to a lack of research regarding SimP within the field of speechlanguage pathology, there is a need to obtain a greater understanding of how Simucase shapes clinical skill development. 
While this research study indicated that participants' competency scores were significantly higher in the assessment mode, further study is needed to better understand the strengths and weaknesses of different Simucase modes in student learning. Further research should also target larger populations of undergraduate student clinicians that share a similar patient demographics in order to determine the impact of Simucase as a method for teaching clinical skills. In addition, future studies might examine the impact of the students' learning and engagement on clinical case competency scores. There is still a greater need for understanding how students learn to utilize SimP and how teachers can utilize SimP to facilitate learning opportunities within the field of speech-language pathology following the completion of each intervention SimP case. In addition, research should continue to explore the students' motivation and interest in each SimP case as well as the students' engagement in each case. From there, research will allow students to understand how their engagement within a clinical case will impact the development of their clinical skills. 


\section{REFERENCES}

American Speech-Language-Hearing Association. (2014). Standards and implementation procedures for the certificate of clinical competence in speech-language pathology. Retrieved from: https://www.asha.org/certification/2014-speech-language-pathologycertification-standards/

American Speech-Language-Hearing Association. (2018). Speech sound disorders. Retrieved from: https://www.asha.org/public/speech/disorders/Speech-Sound-Disorders/.

Bánszki, F., Beilby, J., Quail, M., Allen, P. J., Brundage, S. B., \& Spitalnick, J. (2018). A clinical educator's experience using a virtual patient to teach communication and interpersonal skills. Australasian Journal of Educational Technology, 34(3), 60-73.

Bloom, B., Englehart, M. Furst, E., Hill, W., \& Krathwohl, D. (1956). Taxonomy of educational objectives: The classification of educational goals. Handbook I: Cognitive domain. New York, Toronto: Longmans, Green.

Bradley, P. (2006). The history of simulation in medical education and possible future directions. Medical Education, 40(3), 254-262.

Clark, R., Yates, K., Early, S., \& Moulton, K. (2010). An Analysis of the Failure of Electronic Media and Discovery-based learning: Evidence for the performance benefits of Guided Training Methods. In Silber, K.H. \& Foshay, R. (Eds.) Handbook of Training and Improving Workplace Performance, Volume I: Instructional Design and Training Delivery. Somerset, NJ: Wiley. 
Cantrell, M.J. \& Deloney, L.A. (2007). Integration of standardized patients into simulation. Anesthesiology Clinics, 25(2), 377-83

Cantrell, M. A. (2008). The importance of debriefing in clinical simulations. Clinical Stimulations in Nursing, 4, 19-23.

Edwards, H., Franke, M., \& McGuiness, B. (1995). Using simulated patients to teach clinical reasoning. In: Higgs J, Jones M (Eds.) Clinical reasoning in the health professions Butterworth-Heinemann, Oxford, 269-78.

Edwards, H., McGuiness, B., \& Rose, M. (2000). Using simulated patients to teach clinical reasoning. In: Higgs J, Jones M (Eds.) Clinical reasoning in the health professions (2nd ed.). Oxford: Butterworth-Heinemann.

Gaba, D.M. (2004). The future vision of simulation in health care. Quality and Safety in Health Care, $13(1), \mathrm{i} 2-\mathrm{i} 10$.

Hill, A.E., Davidson, B.J., \& Theodoros, D. G. (2013). The performance of standardized patients in portraying clinical scenarios in speech-language therapy. International Journal of Language \& Communication Disorders, 48(6), 613-624.

Hill, A.E., Davidson, B.J., \& Theodoros, D. (2010). A review of standardized patients in clinical education: Implications for speech-language pathology programs. International Journal of Speech Language Pathology 12(3), 259-70.

Johnson, C., Jansen, L., Williams, S., Pantalone, B. \& Ondo, K. (2014a). Developing a successful simulation-based curriculum. Allied Health Media, 2(2),1-8. 
Johnson, C., Jansen, L., Williams, S., Pantalone, B. \& Ondo, K. (2014b). The future of SLP clinical education. Allied Health Media, 2(2), 1-7.

Lysaght, R. \& Hill, A. (2010). The use of standardized patients as an alternative to fieldwork. In L. McAllister, M. Paterson, J. Higgs and C. Bithell (Eds.). Innovations in allied health fieldwork education: A critical appraisal. Rotterdam: Sense Publishers. (Rotterdam: Sense).

MacBean, N., Theodoros, D., Davidson, B., \& Hill, A. E. (2013). Simulated learning environments in speech-language pathology: An Australian response. International Journal of Speech-Language Pathology, 15(3), 345-357.

McWilliam, P. \& Botwinski, C. (2010). Developing a successful nursing objective structured clinical examination. Journal of Nursing Education, x(1), 36.

Mookherjee, S. Change, A., Boscardin, C. K., \& Hauer, K. E. (2013). How to develop a competency-based examination blueprint for longitudinal standardized patient clinical skills assessment. Medical Teacher, 35(11), 883-890.

Rose, T.A., Copley, A., \& Scarinci, N.A. (2017). Benefits of providing an acute simulated learning environment to speech pathology students: An exploratory study [online]. Focus on Health Professional Education: A Multi-disciplinary Journal, 18(3), 44-59.

Rosen, K.R., McBride, J.M., \& Drake, R.L. (2009). The use of simulation in medical education to enhance students' understanding of basic sciences. Med Teach, 31(9), 842-846.

Simucase. (2017). Retrieved from: http://www.simucase.com.

Tamblym, R., Klass, D., Schnabl, G., \& Kopelow, M. (1991). The accuracy of standardized patient presentation. Medical Education, 25, 100-109. 
Taylor, J.S. (2011). The moral aesthetics of simulated suffering in standardized patient performances. Culture, Medicine, and Psychiatry, 35(2), 134-162.

Thacker, A., Crabb, N., Perez, W., Raji, O., \& Hollins, S. (2007). How (and why) to employ simulated patients with intellectual disabilities. The Clinical Teacher, 4(1),15-20.

Vinney, L. A., Friberg, J. C., \& Smyers, M. M. (in press). Perspective-taking as a mechanism to improve metacognition and higher-level thinking in undergraduate speech-language pathology students. To be published by the Journal for the Scholarship of Teaching and Learning in February 2019.

Zraick, R., Allen, R., \& Johnson, S. (2003). The use of standardized patients to teach and test interpersonal and communication skills with students in speech-language pathology. Advanced Health Science Education Theory Practice, 8(3), 237-48.

Zraick, R. (2012). Review of the use of standardized patients in speech-language pathology clinical education. International Journal of Therapy \& Rehabilitation, 19(2), 112-118. 
Table 1

Pre-simulation Survey: Participant Demographics

\begin{tabular}{ccccc}
\hline Participant & Group & $\begin{array}{c}\text { Taken Coursework } \\
\text { in Pre-Clinical } \\
\text { Service Delivery }\end{array}$ & Client & Therapy \\
\hline 1 & A & Yes & Adult & Articulation/Phonology; Language \\
2 & A & Yes & Child & Articulation/Phonology \\
3 & A & Yes & Child & Articulation/Phonology \\
4 & B & Yes & Child & Language; Fluency/Stuttering \\
5 & B & No & Child & Articulation/Phonology; Language \\
\hline
\end{tabular}


Table 2

Pre/Post Simulation Questionnaire Results

\begin{tabular}{lcc}
\hline & $\begin{array}{c}\text { Pre-Simulation } \\
\text { Questionnaire } \\
\text { Mean Rating (SD) }\end{array}$ & $\begin{array}{c}\text { Post-Simulation } \\
\text { Questionnaire } \\
\text { Mean Rating (SD) }\end{array}$ \\
\hline $\begin{array}{l}\text { I am confident in my ability to collect a case } \\
\text { history and communicate with collaborators. }\end{array}$ & $3.4(.54)$ & $3.6(.56)$ \\
$\begin{array}{l}\text { I am confident in my ability to communicate } \\
\text { with collaborators. }\end{array}$ & $4.2(.84)$ & $4(.71)$ \\
$\begin{array}{l}\text { I am confident in my ability to provide } \\
\text { treatment. }\end{array}$ & $3.6(.56)$ & $4.2(.45)$ \\
$\begin{array}{l}\text { I am confident in my clinical judgment and } \\
\text { skills. }\end{array}$ & $3.6(.56)$ & $3.6(.56)$ \\
$\begin{array}{l}\text { I am confident in my ability to collect and take } \\
\text { data. }\end{array}$ & $4.2(.84)$ & $3.8(.45)$ \\
$\begin{array}{l}\text { I am confident in my ability to interrupt } \\
\text { intervention results. }\end{array}$ & $3.4(.89)$ & $3.6(.56)$ \\
$\begin{array}{l}\text { I am confident in my ability to provide } \\
\text { appropriate recommendations. }\end{array}$ & $3.4(.55)$ & $3.6(.56)$ \\
$\begin{array}{l}\text { I am confident in my ability to adapt treatment } \\
\text { plans to meet my client's needs. }\end{array}$ & $4.6(.55)$ & $4.4(.86)$ \\
$\begin{array}{l}\text { I am confident in my ability relate my } \\
\text { coursework knowledge to any given cases. } \\
\text { I am confident in my ability to use Simucase. }\end{array}$ & $3.8(.84)$ & $3.6(.58)$ \\
$\begin{array}{l}\text { I am confident that I made the right clinical } \\
\text { decisions. }\end{array}$ & $1.8(.45)$ & $3.8(.45)$ \\
$\begin{array}{l}\text { I am confident that I am able to learn from my } \\
\text { clinical mistakes. }\end{array}$ & $3.6(.55)$ & $3.2(.45)$ \\
\hline
\end{tabular}

*Note: Questionnaire responses were totaled up across participants and averaged. Responses were based on the following scale: $1=$ Strongly Disagree, $2=$ Disagree, $3=$ Neutral, $4=$ Agree, and $5=$ Strongly Agree to the statement. 
Table 3

Bloom's Taxonomy Data

\begin{tabular}{lccc}
\hline \multicolumn{1}{c}{ Codes } & Total & Learning & Assessment \\
\hline Knowledge & 40 & 24 & 16 \\
Comprehension & $\mathbf{9 6}$ & 59 & 37 \\
Application & 66 & 33 & 33 \\
Analysis & $\mathbf{8 8}$ & 46 & 42 \\
Synthesis & 27 & 12 & 15 \\
Evaluation & 19 & 10 & 9 \\
& 336 & 184 & 152 \\
\hline
\end{tabular}

*Note: It should be noted that these cases and modes were taken in various orders to reduce bias. 
Table 4

Competency Scores for Learning vs. Assessment Mode

\begin{tabular}{lcc}
\hline & Learning Mode & Assessment Mode \\
\hline $\begin{array}{l}\text { Average Competency } \\
\text { Score by Mode* }\end{array}$ & $30 \%$ & $48 \%$ \\
\hline
\end{tabular}

*Note: It should be noted that these cases and modes were taken in various orders to reduce bias. 
Table 5

Competency Scores and Time Spent on Cases Based on Learning and Assessment Modes

\begin{tabular}{cccccc}
\hline Participant & Group & Learning Mode & Time Spent & Advanced Mode & Time Spent \\
\hline 1 & A & 36 & 40 & 75 & 41 \\
2 & A & 23 & 23 & 27 & 30 \\
3 & A & 60 & 43 & 61 & 44 \\
4 & B & 17 & 28 & 36 & 44 \\
5 & B & 12 & 52 & 34 & 63 \\
\hline
\end{tabular}


Table 6

Bloom's Taxonomy Statements

\begin{tabular}{ll}
\hline Bloom's Code & Sample Coded Statements \\
\hline Knowledge & This simulation required knowledge on articulation of /r/, as well as \\
knowledge of how to take data.
\end{tabular}


- I really tried to pay attention to the relevant information and not get distracted by the other information.

- I did not know how to cue the child in treatment to produce the correct response.

- I know that we are aware of writing goals; however, I was unsure how to pick appropriate goals and administer treatment.

- I liked having to figure out how to motivate the client to continue during treatment because I know I can apply these critical skills into the therapy room.

- I made a ton of mistakes in regard to picking objectives, choosing treatment options, and not taking data.

- I will definitely try to work harder on learning how to motivate 8year-old boys and come up with better tactics at fixing my mistakes.

- Listening to his language sample, I had to listen for errors in his speech, and was able to determine he had difficulty saying $/ \mathrm{r} /$ before getting the information from the speech pathologist.

Synthesis

- This exercise helped me get a better sense of what I should do and say in therapy when the client is not wanting to focus on the task at hand.

- I really liked how this simulation gave me an example of how to be more thorough with providing feedback to the client

Evaluation

- I did not take data all that well (see above), so that was one mistake.

- I decided to end therapy because he was not motivated but had still made progress in that session. He was getting more and more impatient, so that is when I decided to call it, because I felt that he may not be giving his best effort. 


\section{APPENDIX A: PRE- AND POST- SIMULATION QUESTIONAIRE}

Please place a check mark in the box that correlates with your answer to each statement.

\begin{tabular}{|c|c|c|c|c|c|}
\hline & $\begin{array}{c}\text { Strongly } \\
\text { Agree }\end{array}$ & Agree & Neutral & Disagree & $\begin{array}{l}\text { Strongly } \\
\text { Disagree }\end{array}$ \\
\hline $\begin{array}{l}\text { I am confident in my ability to } \\
\text { collect a case history and } \\
\text { communicate with collaborators. }\end{array}$ & & & & & \\
\hline $\begin{array}{l}\text { I am confident in my ability to } \\
\text { communicate with collaborators. }\end{array}$ & & & & & \\
\hline $\begin{array}{l}\text { I am confident in my ability to } \\
\text { provide treatment. }\end{array}$ & & & & & \\
\hline $\begin{array}{l}\text { I am confident in my clinical } \\
\text { judgment and skills. }\end{array}$ & & & & & \\
\hline $\begin{array}{l}\text { I am confident in my ability to } \\
\text { collect and take data. }\end{array}$ & & & & & \\
\hline $\begin{array}{l}\text { I am confident in my ability to } \\
\text { interrupt intervention results. }\end{array}$ & & & & & \\
\hline $\begin{array}{l}\text { I am confident in my ability to } \\
\text { provide appropriate } \\
\text { recommendations }\end{array}$ & & & & & \\
\hline $\begin{array}{l}\text { I am confident in my ability to adapt } \\
\text { treatment plans to meet my client's } \\
\text { needs. }\end{array}$ & & & & & \\
\hline $\begin{array}{l}\text { I am confident in my ability relate } \\
\text { my coursework knowledge to any } \\
\text { given case. }\end{array}$ & & & & & \\
\hline $\begin{array}{l}\text { I am confident in my ability to use } \\
\text { Simucase. }\end{array}$ & & & & & \\
\hline $\begin{array}{l}\text { I am confident that I made the right } \\
\text { clinical decisions. }\end{array}$ & & & & & \\
\hline $\begin{array}{l}\text { I am confident that I am able to } \\
\text { learn from my clinical mistakes. }\end{array}$ & & & & & \\
\hline
\end{tabular}




\section{APPENDIX B: PRE-SIMULATION SURVEY}

Please select the answer or answers that correlate to each statement in regard to your patient and your clinical treatment coursework.

1. What group were you assigned to?
a. Group A
b. Group B

2. In regard to the Clinical Processing and Treatment Class:
a. I have taken the Clinical Processing and Treatment Class.
b. I am currently enrolled in the Clinical Processing and Treatment Class.
c. I have not taken the Clinical Processing and Treatment Class.

3. Is your patient an adult or a child?
a. Adult
b. Child

4. What is your patient's age demographic?
a. 2-4 years old
b. 5-11 years old
c. 12-17 years old
d. 18-49 years old
e. 50-64 years old
f. Older than 65 years old

5. What type of therapy is your client receiving?
a. Articulation/Phonology
b. Receptive/Expressive Language
c. Cognitive Communication
d. Communication Modalities
e. Fluency/Stuttering
f. Voice/Resonance
g. Hearing/Aural Rehab

6. Does your client identify with any of the following?
a. Hearing loss
b. Individual with Aphasia
c. Individual with Down syndrome
d. Individual who uses an AAC device

7. Is your patient culturally diverse?
a. Yes
b. No 


\section{APPENDIX C: REFLECTION QUESTIONS}

Please answer the following questions after the completion of each Simucase in regard to your clinical experience and skills when using Simucase:

1. Explain how this experience helped or hindered your learning about clinical practice as a speech-language pathologist (i.e. What were you expecting? What information did you use from your course work?)

2. Describe your ability to gather data during the simulation (i.e. How did you decide what was important? How did you know?)

3. Evaluate your performance as the clinician within the session (i.e. What did you do well? What mistakes were made? What are you proud of?)?

4. How will you apply this information in the therapy room? What could you do and what could have been done differently?

Please answer the following questions after the completion of each Simucase in regard to your experience using Simucase:

1. What did you view as the positive and negative using Simucase?

2. Did you find this case interesting? Why or Why Not?

3. Describe how you have used this simulated case to facilitate your learning within the classroom and clinic.

4. What knowledge from prior coursework was needed to work with your simulated patient?

5. What information do you wish you were aware of before starting this simulated case?

6. How did you approach the learning and assessment mode? 